\title{
Distinct molecular components for thalamic- and cortical-dependent plasticity in the lateral amygdala
}

\author{
Osvaldo Mirante ${ }^{1,2}$, Federico Brandalise ${ }^{1}$, Johannes Bohacek ${ }^{1,2}$ and Isabelle M. Mansuy $y^{1,2}$ * \\ 'Brain Research Institute, Medical Faculty, University Zürich, Zürich, Switzerland \\ ${ }^{2}$ Department of Health Science and Technology, Swiss Federal Institute of Technology, Zürich, Switzerland
}

\section{Edited by: \\ Bernard Attali, Tel Aviv University, Israel}

\section{Reviewed by:}

Peter Jedlicka, Goethe University, Germany

Baojin Ding, University of

Massachusetts Medical School, USA

\section{*Correspondence}

Isabelle M. Mansuy, Brain Research Institute, Medical Faculty, University

Zürich, Winterthurerstrasse 190,

Zürich 8057, Switzerland

e-mail:mansuy@hifo.uzh.ch
$\mathrm{N}$-methyl-D-aspartate receptor (NMDAR)-dependent long-term depression (LTD) in the lateral nucleus of the amygdala (LA) is a form of synaptic plasticity thought to be a cellular substrate for the extinction of fear memory. The LA receives converging inputs from the sensory thalamus and neocortex that are weakened following fear extinction. Combining field and patch-clamp electrophysiological recordings in mice, we show that paired-pulse low-frequency stimulation can induce a robust LTD at thalamic and cortical inputs to LA, and we identify different underlying molecular components at these pathways. We show that while LTD depends on NMDARs and activation of the protein phosphatases PP2B and PP1 at both pathways, it requires NR2B-containing NMDARs at the thalamic pathway, but NR2C/D-containing NMDARs at the cortical pathway. LTD appears to be induced post-synaptically at the thalamic input but presynaptically at the cortical input, since postsynaptic calcium chelation and NMDAR blockade prevent thalamic but not cortical LTD. These results highlight distinct molecular features of LTD in LA that may be relevant for traumatic memory and its erasure, and for pathologies such as post-traumatic stress disorder (PTSD).

Keywords: LTD, NR2B, NR2C/D, amygdala, phosphatase, mice, PP1

\section{INTRODUCTION}

Synaptic plasticity, a property of neuronal connections characterized by a change in synaptic strength following neuron activation, is essential for memory formation but also for forgetting. Whether presynaptic stimulation increases or decreases synaptic strength depends on the magnitude of post-synaptic calcium elevation (Citri and Malenka, 2008). Long-term potentiation (LTP), a form of synaptic strengthening, is induced by a high rise in intracellular calcium concentration leading to activation of protein kinases. In contrast, long-term depression (LTD), a form of synaptic weakening, requires a moderate rise of intracellular calcium concentration that activates protein phosphatases including PP2B (calcineurin) and subsequently PP1 (Mulkey et al., 1993, 1994; Jouvenceau et al., 2003, 2006; Pi and Lisman, 2008). Once activated, PP1 dephosphorylates some of its targets in synaptic terminals (Morishita etal., 2001), in particular, post-synaptic NMDAR and AMPAR subunits, leading to NMDAR downregulation and AMPAR endocytosis, ultimately resulting in synaptic depression [for review, see (Mansuy and Shenolikar, 2006)].

In the lateral amygdala (LA), LTP is associated with the formation of fear memory (McKernan and Shinnick-Gallagher, 1997; Rogan et al., 1997; Tsvetkov et al., 2002), while LTD is thought to underlie the extinction of fear memory (Kim et al., 2007; Hong et al., 2009; Park et al., 2012). Molecular manipulations that interfere with fear extinction do indeed impair LTD (Lin et al., 2003a,b; Dalton et al., 2008, 2012; Ryu et al., 2008). The LA is a complex limbic structure that integrates sensory information from corti$\mathrm{cal}$ and thalamic afferents. These afferents are highly plastic (Pape and Pare, 2010; Johansen et al., 2011) and converge onto single neurons in LA (Humeau et al., 2005). To date, LTD in LA has been mostly studied at the thalamic pathway, essentially because it is easier to induce than at the cortical pathway (Heinbockel and Pape, 2000; Albrecht, 2007; Tchekalarova and Albrecht, 2007). Similar to fear extinction (Falls et al., 1992; Sotres-Bayon et al., 2007; Liu et al., 2009; Dalton et al., 2012), LTP at the thalamic pathway depends on NMDARs and is primarily associated with the NR2B subunit (Wang and Gean, 1999; Sotres-Bayon etal., 2007; Müller et al., 2009; Yu et al., 2010; Dalton et al., 2012). In contrast, the mechanisms of LTD at the cortical pathway remain unknown, but are postulated to be different from those at the thalamic pathway (Doyere et al., 2003; Humeau et al., 2003). We investigated these mechanisms in adult mouse LA and examined whether they involve the phosphatases PP2B and PP1, and which NMDAR subunits they recruit. Here we show that both PP2B and PP1 are involved in LTD in the amygdala, but that distinct NMDAR subunits are implicated at thalamic and cortical pathways. While LTD depends on NR2B-containing NMDARs at the thalamic pathway, it requires NR2C/D-containing NMDARs at the cortical pathway. We also show that LTD is induced postsynaptically at the thalamic pathway, but not at the cortical pathway.

\section{MATERIAL AND METHODS ANIMALS}

For all experiments, adult male mice C57Bl/6 (8-12 weeks old) were used. Animals were housed in standard housing conditions in a temperature- and humidity-controlled facility on a $12 \mathrm{~h}$ reversed light/dark cycle. Mice had free access to food and water. All procedures were carried out in accordance with the guidelines of the Veterinary Office of the Canton of Zurich, Switzerland, 
and approved by its Commission for Animal Research (License numbers 150/2006 and 105/2008).

\section{SLICES PREPARATION}

Mice were anesthetized with isoflurane 99.9\% (AttaneTM) and rapidly decapitated. Immediately after decapitation, the brain was extracted and sectioned in coronal slices $(400 \mu \mathrm{m}$ thick for extracellular field recordings, $300 \mu \mathrm{m}$ for whole-cell patch clamp recordings) in ice-cold modified artificial cerebrospinal fluid (aCSF) containing $175 \mathrm{mM}$ sucrose, $20 \mathrm{mM} \mathrm{NaCl}, 3.5 \mathrm{mM}$ $\mathrm{KCl}, 1.25 \mathrm{mM} \mathrm{NaH} 2 \mathrm{PO} 4,26 \mathrm{mM} \mathrm{NaHCO} 3,1.3 \mathrm{mM} \mathrm{MgCl}$, and $11 \mathrm{mM} \mathrm{D-(+)-glucose,} \mathrm{and} \mathrm{gassed} \mathrm{with} 95 \% \mathrm{O}_{2} / 5 \% \mathrm{CO}_{2}$ using a vibratome (VT 1000S; Leica Microsystems, Bannockburn, IL, USA). Coronal slices were placed in a holding chamber at $34^{\circ} \mathrm{C}$ and incubated in normal aCSF containing $119 \mathrm{mM} \mathrm{NaCl}$, $2.5 \mathrm{mM} \mathrm{KCl}, 1.3 \mathrm{mM} \mathrm{NaH} \mathrm{PO}_{4}, 26 \mathrm{mM} \mathrm{NaHCO} 3,1.3 \mathrm{mM}$ $\mathrm{MgCl}_{2}, 2.5 \mathrm{mM} \mathrm{CaCl}_{2}$, and $11 \mathrm{mM} \mathrm{D-}(+)$-glucose, and continuously bubbled with $95 \% \mathrm{O}_{2} / 5 \% \mathrm{CO}_{2}$ at $34^{\circ} \mathrm{C}$ for at least $2.5 \mathrm{~h}$, prior to recording. For recording, slices were transferred to a superfusion $(1.5-2.5 \mathrm{ml} / \mathrm{min}$ flow rate) chamber (Warner Instruments) heated at $33.5-34^{\circ} \mathrm{C}$ and held below a platinum wire.

\section{ELECTROPHYSIOLOGY}

The recording electrode was placed in the dorsal part of the LA, and the stimulation electrodes were placed close to the internal capsule and externally to the capsule to stimulate fibers originating from the thalamus or auditory cortex, respectively (see Figure 1A). Extracellular field excitatory post-synaptic potentials (fEPSPs) were recorded from the dorsal part of the LA, while basal single-electrical stimuli at $0.05 \mathrm{~Hz}$ were applied at both pathways. After $10 \mathrm{~min}$ of stable baseline fEPSPs recording, paired pulse low-frequency stimulation [ppLFS, 900 pulses at $1 \mathrm{~Hz}$, interstimuli interval (ITI) of $40 \mathrm{~ms}$ ] was used to induce LTD (Müller et al., 2009). To test input specificity, ppLFS was induced at only one pathway (ppLFS pathway) whereas the other pathway was used as control and was stimulated with $0.05 \mathrm{~Hz}$ baseline stimulation. fEPSPs were recorded using a glass pipette (2-4 M $\Omega$ of resistance) filled with normal aCSF. An input/output (I/O) response curve was established by varying the intensity of single-pulse stimulation. The stimulus intensity that evoked a fEPSP equal to $50 \%$ of the maximum response was used for all stimulations. fEPSPs were amplified (Multiclamp 700B), filtered (low-pass filter $1 \mathrm{kHz}$, high-pass filter $1 \mathrm{~Hz}$ ) and digitized at $10 \mathrm{kHz}$ (Axoclamp 10.2). Whole-cell recordings were performed in a blind approach (Castaneda-Castellanos et al., 2006). The patch pipette (4-8 $\mathrm{M} \Omega$ resistance) was filled with a solution containing (in $\mathrm{mM}$ ): potassium gluconate $126, \mathrm{NaCl} 4, \mathrm{MgSO} 4$ 1, BAPTA-free 0.1, BAPTA-Ca ${ }^{2+} 0.05$, glucose 15, ATP 3, HEPES 5 (pH was adjusted to 7.2 with $\mathrm{KOH}$ ) and GTP 0.1. Membrane potential was measured relative to an agar-bridge reference electrode. Reported membrane potential values were adjusted off-line for liquid-junction potentials (usually $<5 \mathrm{mV}$ ). Voltage-clamp mode was used to record evoked excitatory post-synaptic currents (eEPSCs) from thalamic and cortical pathways. After stable baseline recording for at least $10 \mathrm{~min}$, ppLFS stimulation was delivered in currentclamp configuration. Before and after ppLFS, series resistance was monitored by measuring the passive current transients induced by $10 \mathrm{mV}$ hyperpolarizing voltage steps from a holding potential of $-60 \mathrm{mV}$. Accepted deviations from this parameter in current transients recorded over the time-windows used for statistical analysis were $<10 \%$ (Brandalise et al., 2012). Data were recorded using an Axopatch 200B amplifier, sampled with a Digidata1440 interface (sampling time $=250 \mathrm{msec}$ for current-clamp recording, $10 \mathrm{~ms}$ for voltage-clamp recordings) and analyzed with P-CLAMP software (Axon Instruments, Foster City, CA, USA) and Origin software (Microcal Software, Northhampton, MA, USA).

\section{DRUG APPLICATION}

All drugs were bath applied at the indicated concentration starting at least $45 \mathrm{~min}$ before ppLFS and throughout recording, except D-(-)-2-Amino-5-phosphonopentanoic acid (D-APV, $50 \mu \mathrm{M}$, Tocris), which was perfused for $10 \mathrm{~min}$, starting $5 \mathrm{~min}$ prior to ppLFS delivery. To block specific NMDAR subunits, the NR2B antagonists ifenprodil hemitartrate $(10 \mu \mathrm{M}$, Tocris) and Co101244 (1 $\mu \mathrm{M}$, Tocris) were used, and the NR2C/Dantagonist $[ \pm]$-cis-1-[phenanthren-2yl-carbonyl]piperazine-2,3dicarboxylic acid (PPDA, Tocris, $0.25 \mu \mathrm{M}$ to preferentially block NR2C/D-containing receptors and $1 \mu \mathrm{M}$ to block NR2 subunits nonspecifically). FK-506 (100 $\mu \mathrm{M}$, Tocris) and tautomycetin ( $4 \mathrm{nM}$, Tocris) were used to antagonize PP2B and PP1 activity, respectively (Mitsuhashi et al., 2001; Jouvenceau et al., 2003). The calcium chelator 1,2-bis(o-aminophenoxy)ethane$N, N, N^{\prime}, N^{\prime}$-tetraacetic acid (BAPTA, $100 \mathrm{mM}$, Tocris) and the NMDAR open-channel blocker MK-801 (Dizocilpine, $40 \mu \mathrm{m}$, Tocris) were dialysed in individual post-synaptic LA neurons for $>10 \mathrm{~min}$ through the patch pipette. To specifically and fully block activated NMDARs during MK-801 dialysis, cells were progressively depolarized from the holding potential of $-70 \mathrm{mV}$ to $+30 \mathrm{mV}$, while thalamic or cortical pathways were stimulated about 200-300 times to allow irreversible binding of MK-801 to activated post-synaptic NMDARs (Humeau et al., 2003; Yang et al., 2008). Consequently, the post-synaptic NMDAR component of EPSC activity was reduced after MK801 dialysis (charge transfer reduced by $28.6 \pm 9.5 \% n=3$ for the thalamic pathway, and $17.2 \pm 6.7 \% n=3$ for the cortical pathway). Cells were clamped again at $-70 \mathrm{mV}$ for another $10 \mathrm{~min}$ showing no significant change in the peak amplitude of AMPAR-mediated responses.

\section{DATA ANALYSIS}

Data analysis was performed using Clampfit software (v10.2, Molecular Devices, Sunnyvale, DA, USA), GraphPad Prism (GraphPad Software Inc., San Diego, CA, USA), and Excel (Microsoft). For all recordings, fEPSP slope, and EPSP and EPSC amplitude were normalized to the average of baseline slope and amplitude, respectively. To improve the signal-to-noise ratio, data were averaged into $1 \mathrm{~min}$ bins. For each experiment, two to three slices per animal were recorded, one was always used as control slice and one or two slices received drug-treatment. For statistical analyses, individual animals (not slices) were considered biological replicates. For both extracellular field and whole-cell recordings, data are expressed as mean \pm SEM. Statistical comparisons were 


\section{A Thalamic}

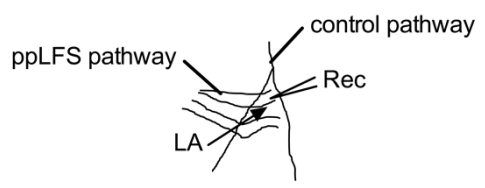

\section{B Thalamic}

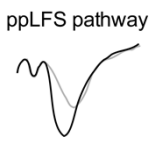

- ppLFS pathway

- Control pathway

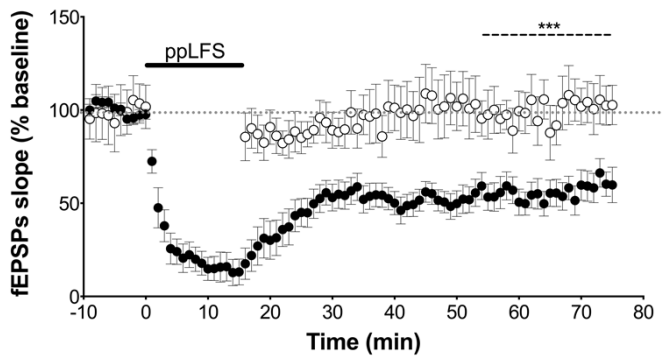

C Thalamic
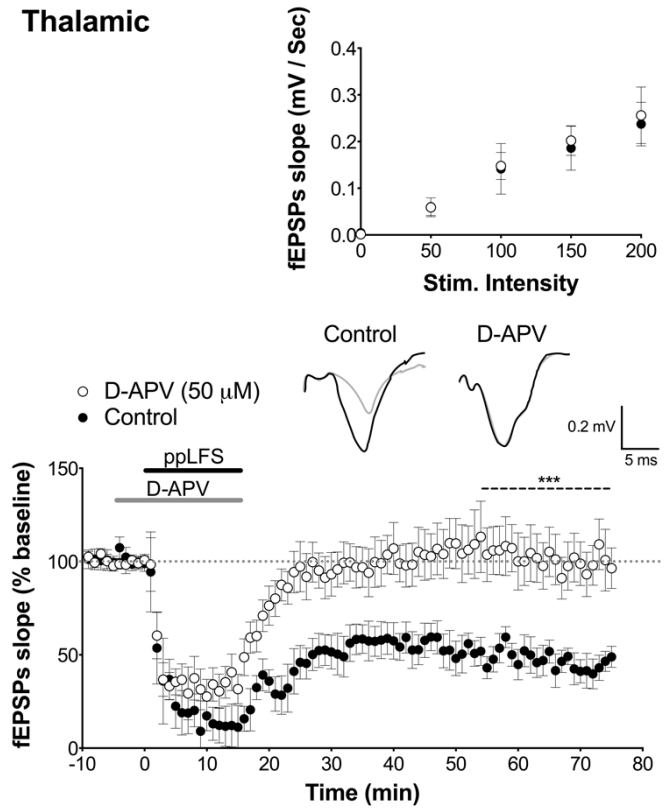

FIGURE 1 | Input-specific NMDAR-dependent LTD at the thalamic and cortical pathways in the lateral amygdala. (A) Schematic illustration of electrode placement for ppLFS and control pathway recording of the thalamic pathway (left) and the cortical pathway (right). (B) Robust, long-lasting LTD was specifically induced at the pathway receiving ppLFS (thalamic, $n=18$; cortical, $n=18$ ) but not at the control pathway (thalamic: $n=11$; cortical: $n=14$ ). Insets show representative traces of extracellular field potentials

\section{Cortical}

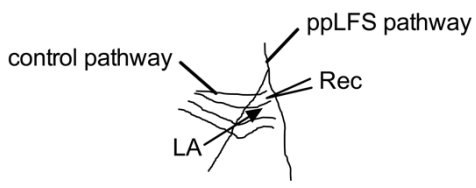

\section{Cortical}
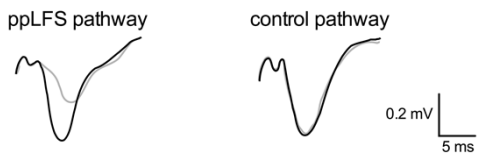

- ppLFS pathway

- Control pathway

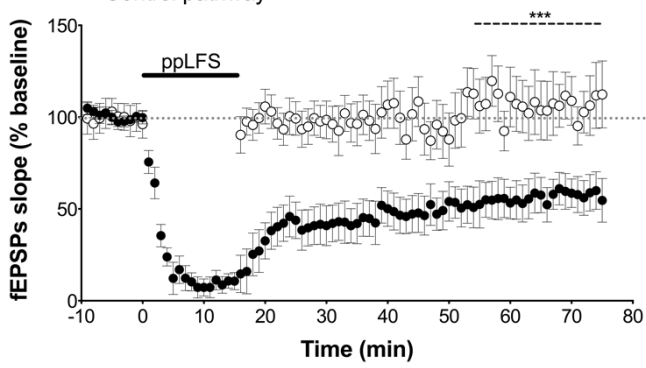

Cortical
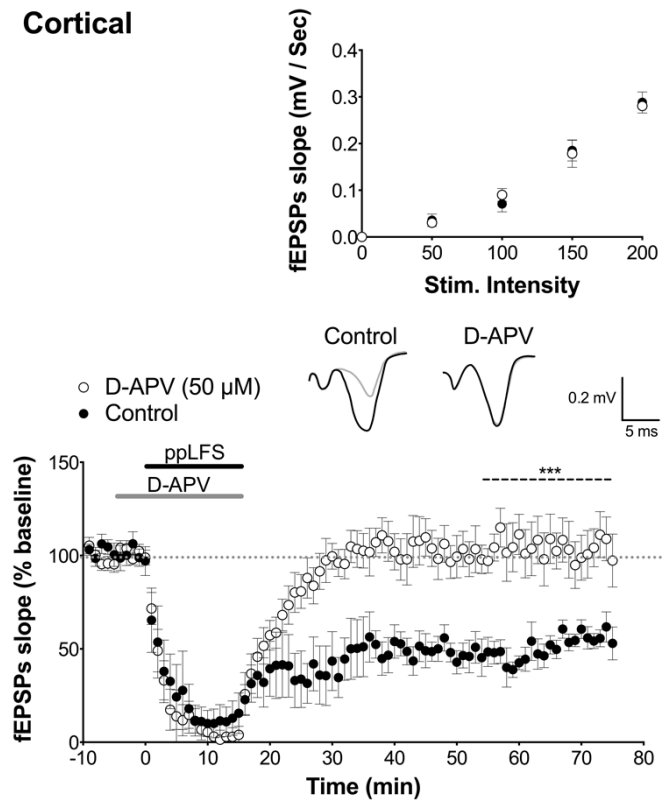

averaged across $10 \mathrm{~min}$ before ppLFS (black line) and the last 10 min of recording after ppLFS (gray line). (C) D-APV $(50 \mu \mathrm{M})$ prevents LTD at thalamic afferents (control: $n=6$; D-APV: $n=9$ ) and at cortical afferents (control: $n=5$; D-APV: $n=9$ ). Insets show $1 / 0$ curves on top and below representative traces of extracellular field potentials averaged across $10 \mathrm{~min}$ before ppLFS (black line) and the last 10 min of recording after ppLFS (gray line). Data represent mean \pm SEM. ${ }^{* * *} p<0.001$. 
performed using Student's unpaired $t$-tests when two groups were compared. One-way ANOVAs were used when more than two groups were compared. If significant, ANOVAs were followed using Duncan's post hoc test. Significance was set to $p<0.05$.

\section{RESULTS PATHWAY-SPECIFIC LTD IN LA}

Using extracellular field recording, we first assessed whether a paired-pulse low frequency stimulation protocol (ppLFS) induces stable and input-specific LTD at thalamic and cortical afferents to the LA in slices from adult mouse (for electrode placement see Figure 1A). A robust LTD that lasted over 1 hr was specifically induced at the pathway receiving ppLFS but not at a control pathway, both at thalamic (ppLFS pathway: $53.3 \pm 4.3 \%, n=18$ vs. control pathway: $106.2 \pm 10.9 \%, n=11, p<0.001$, Figure 1B) and cortical input (ppLFS pathway: $52.7 \pm 3.6 \%, n=18$ vs. control pathway: $108.6 \pm 12.2 \%, n=14, p<0.001$, Figure 1B). The magnitude of fEPSP suppression was comparable between thalamic and cortical ppLFS $(p>0.9)$. These results indicate that the ppLFS protocol leads to a strong and input-specific induction of LTD (LA-LTD) at both thalamic and cortical pathways to LA.

\section{NMDAR-DEPENDENT LTD IN LA DEPENDS ON PROTEIN PHOSPHATASES}

In the hippocampus, the most common form of LTD requires post-synaptic rise in calcium that depends on NMDARs, and is associated with activation of a PP2B/PP1 signaling cascade (Collingridge etal., 2010). Both PP2B and PP1 are known to be negative regulators of plasticity that further, can act as memory suppressors (Mansuy et al., 1998; Malleret et al., 2001; Genoux etal., 2002). We thus first tested whether LALTD is NMDAR-dependent at both pathways using extracellular field recordings. LTD was fully blocked by the NMDAR antagonist D-APV $(50 \mu \mathrm{M})$ at both, the thalamic (control: $50.6 \pm 5.6 \%, n=6$; D-APV: $103.0 \pm 10.4 \%, n=9$, $p<0.001$, Figure 1C) and cortical (control: $53.7 \pm 2.9 \%$, $n=5$; D-APV: $114.8 \pm 9.9 \%, n=9, p<0.001$, Figure 1C) pathway, demonstrating that LA-LTD depends on NMDARs at both pathways. Input/output $(\mathrm{I} / \mathrm{O})$ curves were not affected by D-APV, suggesting that basal synaptic transmission was not altered (Figure 1C, insets). Next, we examined whether PP2B and PP1 are involved in LA-LTD. Perfusion of the selective PP2B inhibitor FK-506 $(100 \mu \mathrm{M})$ abolished LTD at both, thalamic (control: $54.9 \pm 1.9 \%, n=5$; FK-506: $102.4 \pm 10.9 \%, n=5, p<0.01$, Figure 2A) and cortical (control: $48.3 \pm 2.5 \%, n=5$; FK506: $96.0 \pm 5.0 \%, n=5, p<0.001$, Figure 2A) pathways. Similarly, bath application of the specific PP1 inhibitor tautomycetin (4 nM) abolished LA-LTD at both pathways (Thalamic, control: $57.5 \pm 5.2 \%, n=5$; tautomycetin: $101.4 \pm 5.9 \%$, $n=10, p<0.001$. Cortical, control: $52.4 \pm 6.7 \%, n=7$; tautomycetin: $118.2 \pm 20.8 \%, n=8, p<0.05$, Figure 2B). $\mathrm{I} / \mathrm{O}$ curves were not affected by FK-506 (Figure 2A, insets) or tautomycetin (Figure 2B, insets), suggesting that basal synaptic transmission was not altered. These results show that LA-LTD requires $\mathrm{PP} 2 \mathrm{~B}$ and $\mathrm{PP} 1$ at both thalamic and cortical pathways.

\section{LA-LTD DEPENDS ON ACTIVATION OF DIFFERENT NR2 SUBUNITS AT THALAMIC AND CORTICAL AFFERENTS}

We next investigated the NMDAR subunit composition implicated in LA-LTD at both inputs. While NR2A-containing receptors have previously been suggested to be involved in LTP in different brain structures, NR2B-containing receptors are thought to be involved in LTD (Liu et al., 2004; Massey et al., 2004; Bartlett et al., 2007; Banerjee etal., 2009; Dalton etal., 2012), particularly in LA-LTD at the thalamic input (Yu et al., 2010; Dalton et al., 2012). At the cortical pathway, however, the NMDAR subunit composition is still unclear (Weisskopf and LeDoux, 1999; Müller et al., 2009). To test whether NR2B is required for LTD at both pathways, we used the selective NR2B antagonists ifenprodil $(10 \mu \mathrm{M})$ and Co101244 $(1 \mu \mathrm{M})$. While both antagonists fully blocked LTD at the thalamic pathway (control: $54.7 \pm 5.7 \%$, $n=5$; ifenprodil: $118.0 \pm 16.0 \%, n=8$; Co101244: $98.0 \pm 10.5 \%$, $n=5, p<0.05$ in both cases, Figure 3), they had no effect on LTD at the cortical pathway (control: $55.2 \pm 5.9 \%, n=5$; ifenprodil: $48.2 \pm 5.2 \%, n=6$; Co101244: $52.5 \pm 12.2 \%, n=5, p>0.8$, Figure 3). Ifenprodil and Co101244 did not affect I/O curves, suggesting no effect on basal synaptic transmission (Figure 3A, insets). These results demonstrate that LTD at the thalamic pathway is NR2B-dependent, while LTD at the cortical pathway is not.

To determine which other NR2 subunits may be implicated in LTD at the cortical pathway, we next tested the contribution of NR2C/D subunits [NR2A was previously reported not to be involved in LA-LTD (Dalton etal., 2012)]. We used PPDA, a potent and dose-dependent selective NR2C/D antagonist (Hrabetova etal., 2000; Feng etal., 2004). We used PPDA at low concentration $(0.25 \mu \mathrm{M})$ to preferentially antagonize NR2C/D subunits, and at high concentration $(1 \mu \mathrm{M})$ to antagonize all NR2 subunits (Feng et al., 2004). At $0.25 \mu \mathrm{M}$, PPDA fully blocked LALTD specifically at the cortical input, but had no effect at the thalamic pathway (Figure 4). In contrast, $1 \mu \mathrm{M}$ of PPDA abolished LA-LTD at both pathways (thalamic, control: $45.2 \pm 8.5 \%$, $n=7$; PPDA $0.25 \mu \mathrm{M}: 44.3 \pm 9.1 \%, n=5$; PPDA $1 \mu \mathrm{M}$ : $113.6 \pm 20.6 \%, n=6, p<0.01$. Cortical, control: $41.6 \pm 9.8 \%$, $n=6$; PPDA $0.25 \mu \mathrm{M}: 113.3 \pm 14.1 \%, n=6$, PPDA $1 \mu \mathrm{M}$ : $107.1 \pm 22.2 \%, n=6, p<0.05$, Figure 4). I/O curves were not affected by PPDA at either concentration (Figure 4A, insets). Overall, these results indicate that LTD at the thalamic pathway depends on NR2B-containing NMDARs, whereas LTD at the cortical pathway depends on NR2C/D-containing NMDARs.

\section{DISTINCT LOCI OF LTD INDUCTION AT THALAMIC AND CORTICAL PATHWAYS}

Although LTD is generally thought to be induced post-synaptically, it is known that NMDAR-dependent LTD can also occur presynaptically in several brain regions (Casado et al., 2002; Sjostrom et al., 2003; Rodriguez-Moreno and Paulsen, 2008; RodriguezMoreno etal., 2010). NR2B-containing NMDARs are mostly localized post-synaptically (Loftis and Janowsky, 2003; Mameli et al., 2005; Miwa etal., 2008; Yu etal., 2010) and NR2C/Dcontaining NMDARs are mostly presynaptic (Thompson et al., 2002; Mameli etal., 2005; Grilli etal., 2009) and have been 


\section{A Thalamic}
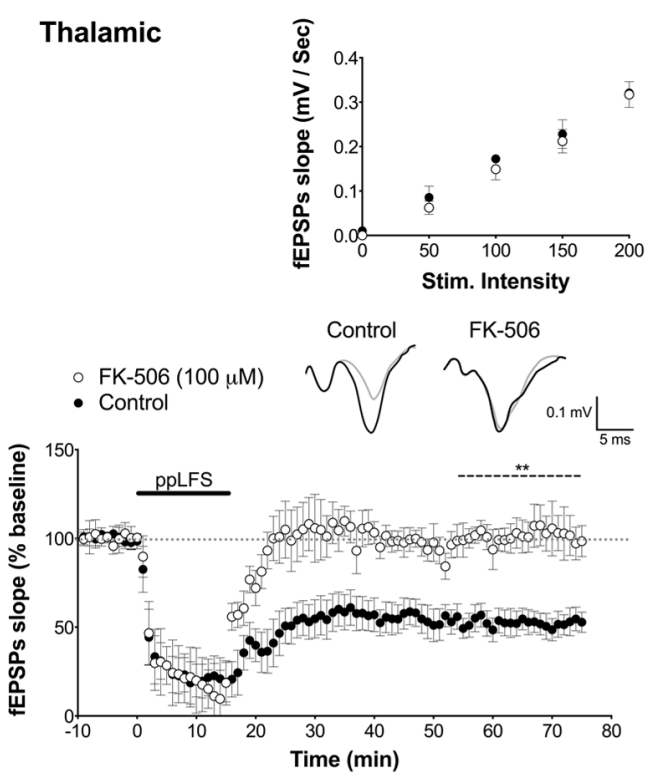

B

Thalamic
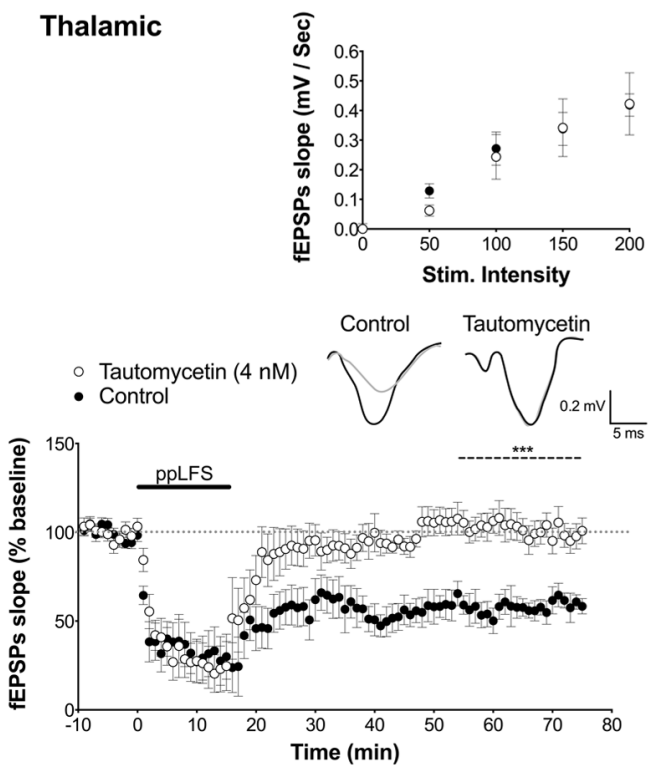

FIGURE 2 | PP2B and PP1 involvement in LTD at the thalamic and cortical pathways in the lateral amygdala. (A) The PP2B antagonist FK-506 $(100 \mu \mathrm{M})$ blocks LTD induced at thalamic afferents (left panel, control: $n=5$; FK-506: $n=5$ ) and at cortical afferents (right panel, control: $n=5$; FK-506: $n=5$ ). (B) The PP1 antagonist tautomycetin $(4 \mathrm{nM})$ blocks LTD induced at thalamic afferents (control: $n=5$;
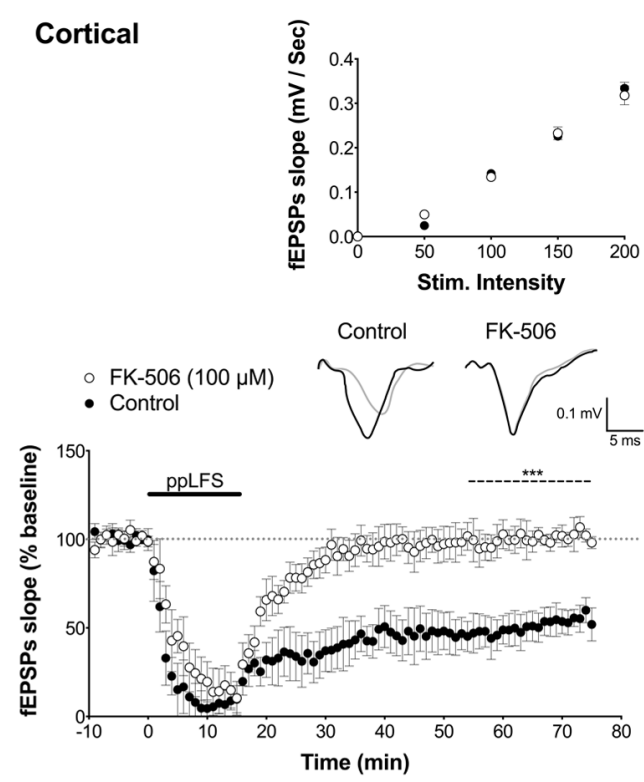

Cortical
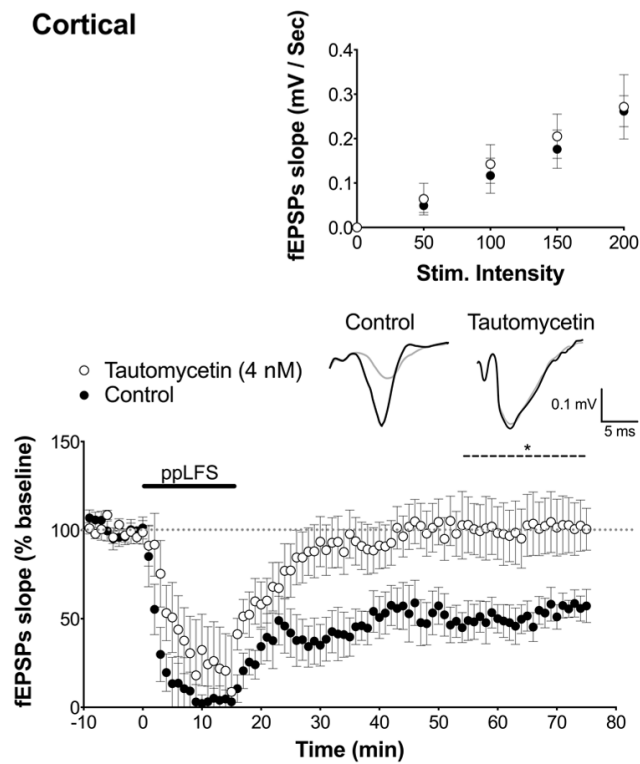

tautomycetin: $n=10$ ), and at cortical afferents (control: $n=7$; tautomycetin: $n=8$ ). Insets show $\mathrm{l} / \mathrm{O}$ curves on top and below representative traces of extracellular field potentials averaged across 10 mins before ppLFS (black line) and the last 10 min of recording after ppLFS (gray line). Data represent mean \pm SEM. ${ }^{* *} p<0.001$, ${ }^{*} p<0.001,{ }^{*} p<0.05$. implicated in presynaptic LTD in the somatosensory cortex (Banerjee etal., 2009). Because NR2B and NR2C/D subunits are differentially involved in LTD at thalamic and cortical pathways, we hypothesized that LTD may have different loci of induction at thalamic and cortical pathways. We tested this hypothesis using whole-cell patch clamp recording in LA pyramidal neurons. The recorded cells $(n=32)$ showed a firing pattern and spike frequency adaptation characteristic of LA pyramidal neurons (Figure 5A; Weisskopf and LeDoux, 1999; Faber et al., 2001). The average resting potential of these neurons was $-67.6 \pm 4.3 \mathrm{mV}$. We observed a mono-exponential relationship between current transients and voltage steps, indicating that excitatory cells in LA behave as single electrical compartments $\left(t_{1}=40.65 \pm 0.1 \mathrm{~ms}\right)$. Transients were also used to estimate series resistance $(15.3 \pm 4.23 \mathrm{M} \Omega)$, input resistance $(235 \pm 42.47 \mathrm{M} \Omega)$ and membrane capacitance $(67.7 \pm 16.8 \mathrm{pF})$, all typical values 


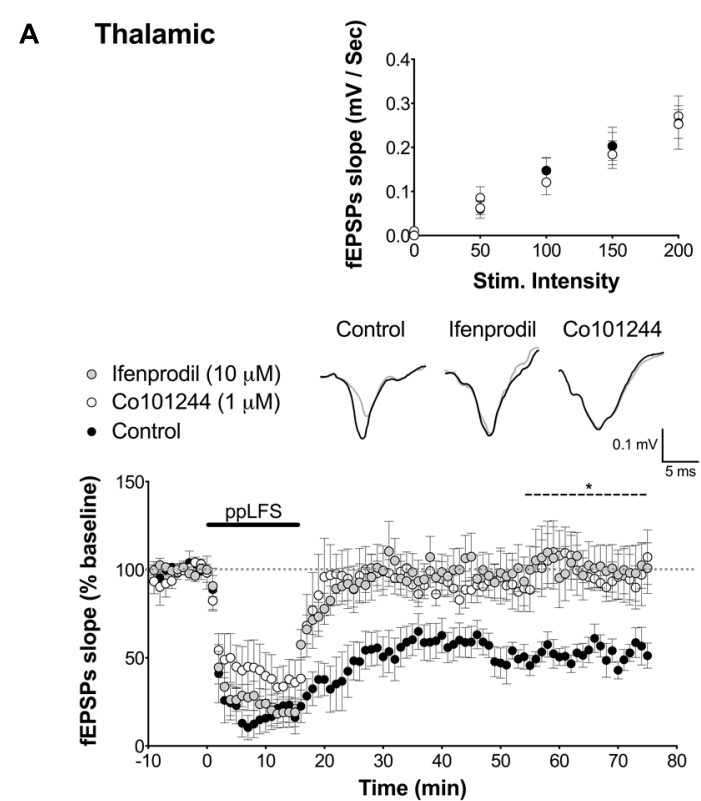

B Thalamic

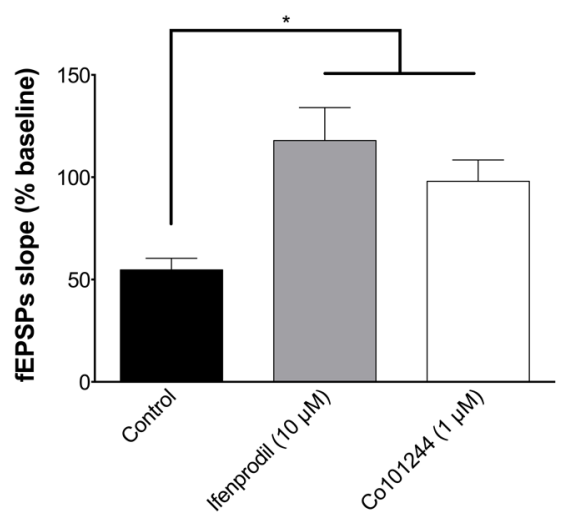

FIGURE 3 | LA-LTD at thalamic inputs specifically depends on NR2B-containing NMDARs. (A) Ifenprodil $(10 \mu \mathrm{M})$ and Co101244 $(1 \mu \mathrm{M})$ block LTD at thalamic afferents (left panel, control: $n=5$; ifenprodil: $n=8$; Co101244: $n=5$ ) but not at cortical afferents (right panel, control: $n=5$; ifenprodil: $n=6$; Co101244: $n=5$ ). (B) Summary of the average fEPSP slope
Cortical
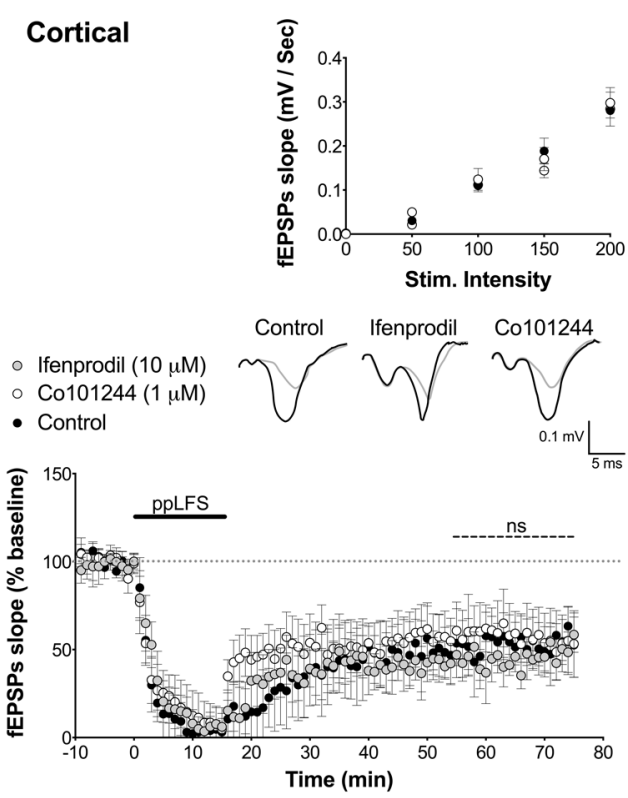

Cortical

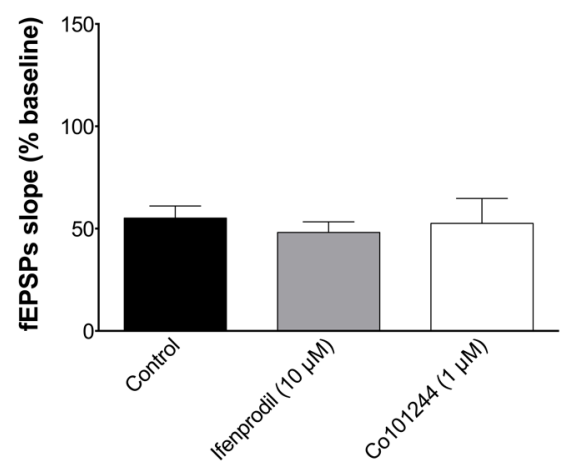

over the last 20 min of recording after ppLFS. Insets show I/O curves on top and below representative traces of extracellular field potentials averaged across $10 \mathrm{~min}$ before ppLFS (black line) and the last $10 \mathrm{~min}$ of recording after ppLFS (gray line). Data represent mean \pm SEM. ${ }^{*} p<0.05$, ns $=$ non significant. for LA excitatory cells (Weisskopf and LeDoux, 1999; Faber et al., 2001).

Before assessing the locus of LTD induction, we examined whether LTD can be induced in individual excitatory LA neurons with the ppLFS protocol in current clamp configuration, and whether it depends on NMDARs. ppLFS induced a robust and persistent LTD in LA neurons, which was similar at thalamic and cortical inputs (thalamic: $47.38 \pm 9.74 \%, n=4$; cortical: $56.2 \pm 4.6 \% n=5, p>0.3$, Figure 5B). LTD was blocked by D-APV, confirming that it is NMDAR-dependent (thalamic: D-APV: $112.5 \pm 3.0 \%, n=3, p<0.001$; cortical: D-APV: $108.1 \pm 6.2 \%, n=3, p<0.01$, Figure 5B). Because post-synaptic plasticity depends on changes in post-synaptic intracellular calcium concentration, we examined whether LTD is post-synaptic by preventing calcium increase at the postsynaptic site using the membrane impermeable calcium chelator BAPTA (100 $\mathrm{mM}$, dialyzed for $20 \mathrm{~min}$ before ppLFS). LTD at the thalamic pathway was fully blocked by BAPTA (control: $47.6 \pm 6.7 \%, n=4$; BAPTA: $98.9 \pm 5.7 \%, n=4$, $p<0.01)$ but it was not affected at the cortical pathway (control: $52.0 \pm 6.6 \%, n=5$, BAPTA: $46.9 \pm 6.1 \%$, $n=5, p>0.5$, Figure 6A). These results suggest that the induction of LTD requires a post-synaptic rise in calcium at thalamo-LA synapses but not at cortico-LA synapses. To further assess the synaptic locus of LTD at thalamic and cortical synapses, we selectively blocked post-synaptic NMDARs before LTD induction by intracellular dialysis of the activity-dependent NMDAR antagonist MK-801 (40 $\mathrm{MM})$ into the pyramidal-like 


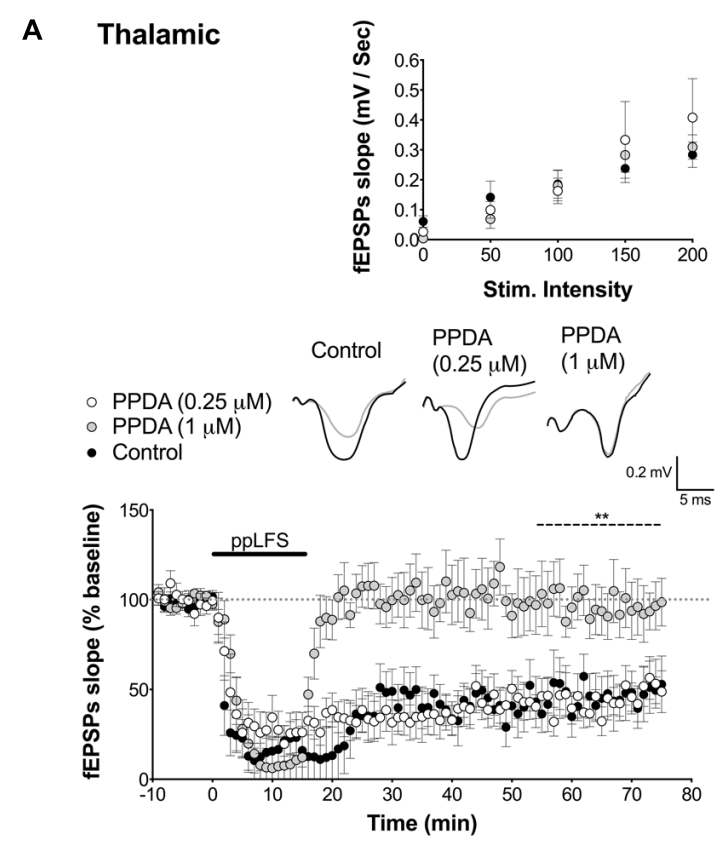

B Thalamic

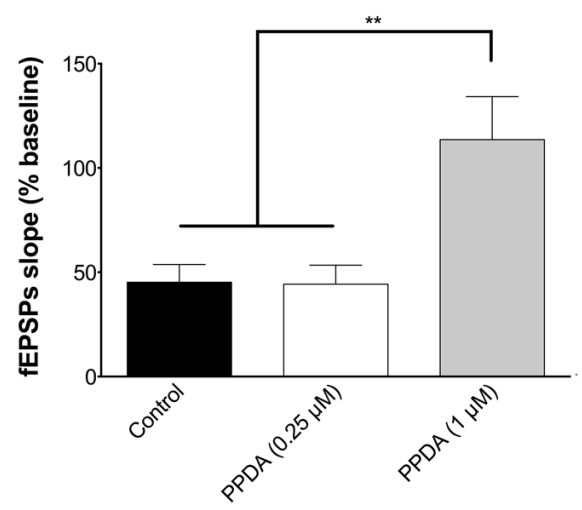

FIGURE 4 | LA-LTD at thalamic inputs specifically depends on NR2C/D-containing NMDARs. (A) PPDA does not affect LTD at the thalamic pathway at the NR2C/D-selective low dose of $0.25 \mu \mathrm{M}$, but blocks LTD at the non-selective high dose of $1 \mu \mathrm{M}$ (left panel, control: $n=7$; PPDA low dose: $n=5$; PPDA high dose: $n=6$ ). PPDA fully blocks LTD and at cortical pathway at both doses (right panel, control: $n=6$; PPDA low dose: $n=6$; PPDA high
LA neuron. In the presence of MK-801, LTD was fully blocked at thalamo-LA synapses (control: $37.9 \pm 13.5 \%, n=3$, MK801: $104.3 \pm 5.4 \%, n=3, p<0.05)$ but was not affected at cortico-LA synapses (control: $52.5 \pm 14.2 \%, n=3$, MK801: $54.8 \pm 11.6 \%, n=3, p>0.9$, Figure 6B), suggesting that LTD requires the activation of post-synaptic NMDARs at thalamic but not cortical synapses. Together, these results support a post-synaptic locus of LA-LTD at the thalamic pathway that likely depends on post-synaptic NMDARs, but a mechanism independent of post-synaptic NMDARs and independent of changes in post-synaptic calcium at the cortical pathway.

\section{Cortical}
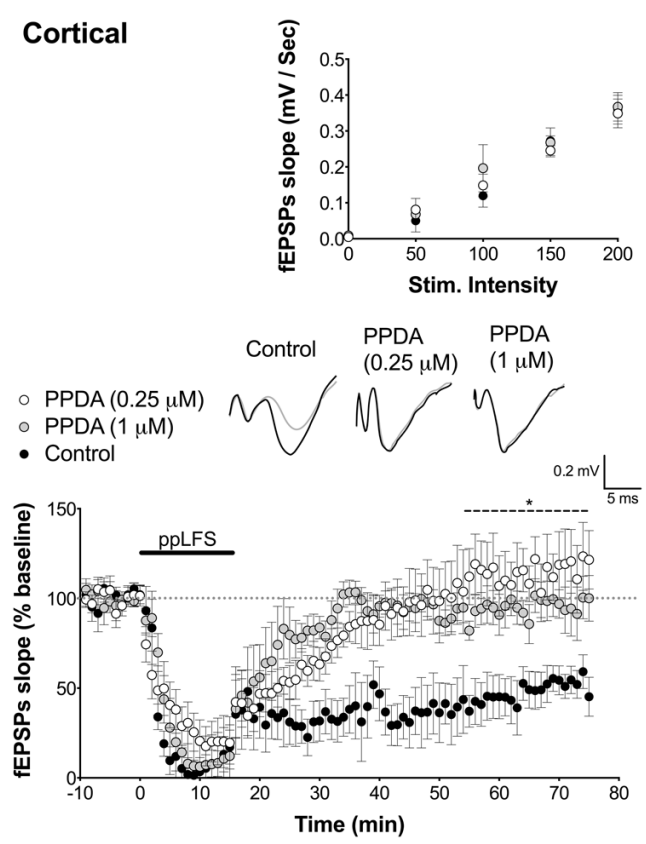

Cortical

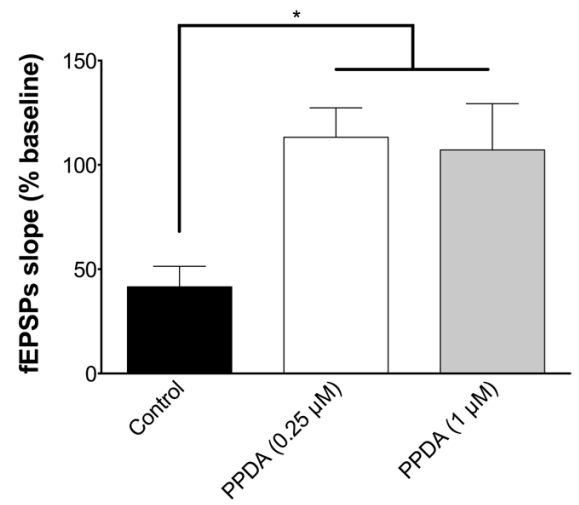

dose: $n=6$ ). (B) Summary of the average fEPSP slope over the last 20 min of recording after ppLFS. Insets show I/O curves on top and below

representative traces of extracellular field potentials averaged across $10 \mathrm{~min}$ before ppLFS (black line) and the last 10 min of recording after ppLFS (gray line). Data represent the mean \pm SEM. ${ }^{* *} p<0.01,{ }^{*} p<0.05$, ns $=$ non significant.

\section{DISCUSSION}

The protein phosphatases $\mathrm{PP} 2 \mathrm{~B}$ and $\mathrm{PP} 1$ are key players in the regulation of synaptic strength, and in the formation and the maintenance of memory traces (Lisman and Zhabotinsky, 2001; Mansuy and Shenolikar, 2006; Baumgärtel and Mansuy, 2012). Activation of PP2B/PP1 signaling is known to be necessary for LTD in different brain regions (Kirkwood et al., 1993; Mulkey et al., 1994; Morishita et al., 2001; Lin et al., 2003b; Yasuda et al., 2003). This study provides novel evidence that these phosphatases are also involved in the induction of LTD in LA at both thalamic and cortical pathways. This finding is in line with previous results showing that depotentiation at the cortical pathway in LA requires PP2B 
A
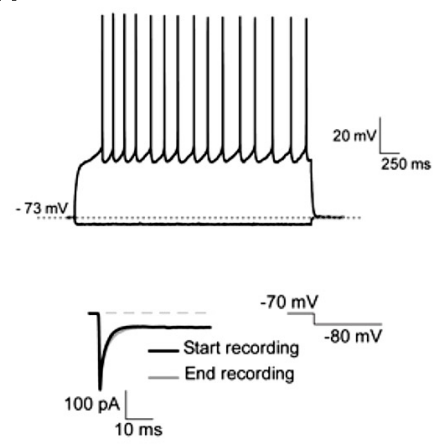

B

Thalamic

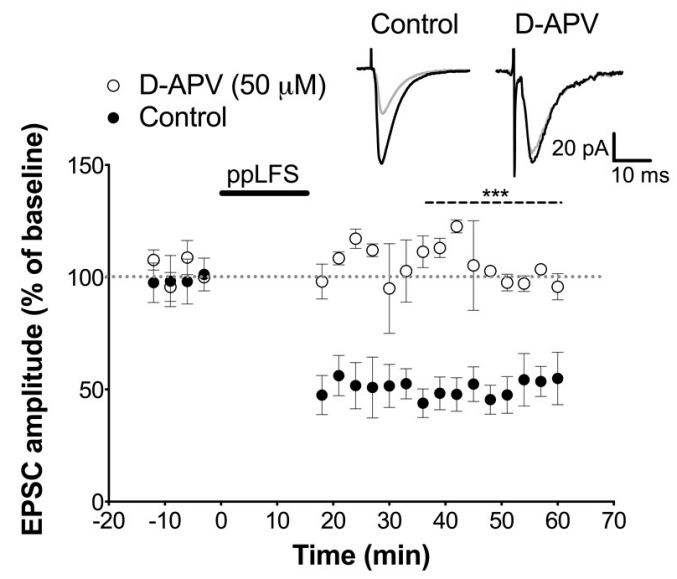

FIGURE 5 | NMDAR-dependent LTD in single pyramidal cells. (A) On top, response of a LA cell to current injection of -0.10 and $+0.15 \mathrm{nA}$ and below, hyperpolarizing voltage steps of $10 \mathrm{mV}$ from a holding potential of $-60 \mathrm{mV}$ were used to measure series resistance.

(B) D-APV $(50 \mu \mathrm{M})$ blocks LA-LTD induced at the thalamic pathway (left

(Lin et al., 2003a), and that PP2B and PP1 play an important role in memory tasks that depend on the amygdala including conditioned taste aversion and extinction of fear memory (Lin et al., 2003b; Baumgärtel et al., 2008; Oberbeck et al., 2010; Koshibu et al., 2011). They also complement findings in the hippocampus that PP2B or PP1 inhibition enhances hippocampal LTP and memory performance in hippocampus-dependent tasks (Malleret et al., 2001; Genoux et al., 2002) but impairs LTD (Jouvenceau et al., 2006). Taken together, these findings support the concept that PP2B/PP1 are key regulators of synaptic plasticity, and that their inhibition favors LTP and memory acquisition, but impairs LTD and memory extinction in both hippocampus and amygdala.

Our finding that LTD at the thalamic LA pathway is NR2Bdependent is consistent with previous studies (Müller et al., 2009; Dalton et al., 2012; Park et al., 2012). NR2B is present in postsynaptic densities (PSD) in LA (Miwa etal., 2008), and LTD at the thalamic pathway depends on NR2B-dependent postsynaptic AMPAR endocytosis (Yu et al., 2010). Surprisingly, we observed that LTD induced at the cortical pathway is independent of NR2B signaling, since NR2B antagonists do not block LTD

\section{Cortical}

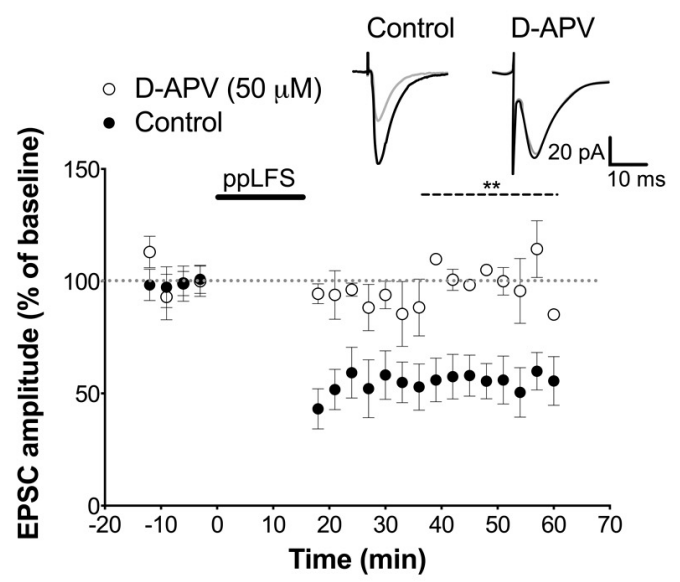

panel, control: $n=4$; D-APV: $n=3$ ), and at the cortical pathway (right panel, control: $n=5$; D-APV: $n=3$ ). Insets show the average of 10 sweeps of a single cell recorded $10 \mathrm{~min}$ before (black) and $30 \mathrm{~min}$ after (gray) ppLFS. Data represent mean \pm SEM. ${ }^{* *} p<0.001$, ${ }^{*} p<0.01$. induction. Instead, we observed that blocking NR2C/D subunits fully prevents LTD at the cortical pathway, but does not affect LTD at the thalamic pathway. The observation that LTD at the cortical pathway is NR2B-independent contrasts with a previous report showing that antagonizing NR2B blocks LTD at both pathways in horizontal slices from adult mice (Müller et al., 2009). This apparent discrepancy likely results from a different orientation of the slices leading to different sites of stimulation and recording. Specifically, placing the stimulating electrode laterally to the internal capsule in coronal slices primarily activates cortical afferents to LA, but in horizontal slices, it also activates afferents from the entorhinal and perirhinal cortex (von Bohlen und Halbach and Albrecht, 2002; Müller et al., 2009). The spatial organization of excitatory and inhibitory connections within the LA depends as well on slice orientation (Samson et al., 2003; Samson and Pare, 2006). It thus needs to be determined whether LTD differentially relies on NR2B or NR2C/D-containing receptors in the cortical pathway depending on the slice orientation. Given our clear finding that thalamic and cortical input to LA rely on different molecular and postsynaptic mechanisms, we postulate that projections to LA from 


\section{A Thalamic}

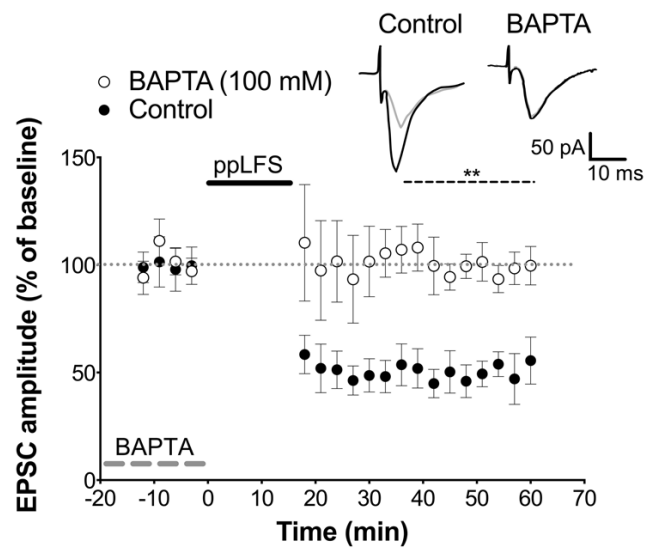

B Thalamic

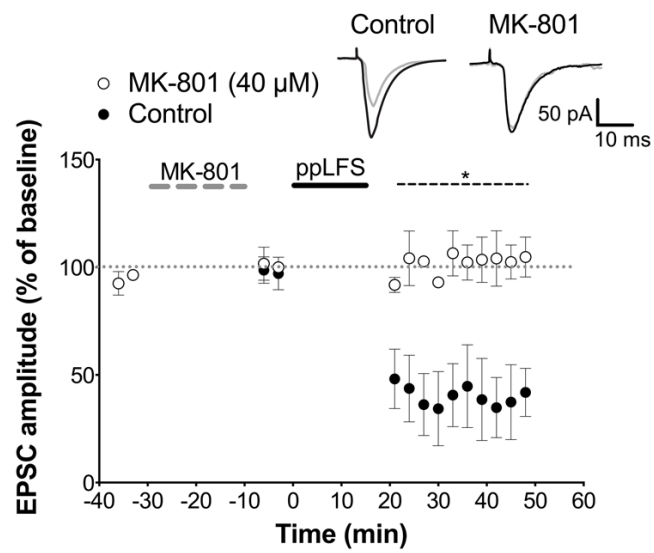

FIGURE 6 | Distinct locus of LTD induction at thalamic and cortical pathways. (A) Dialysis of BAPTA blocks LA-LTD induced at the thalamic pathway (left panel, control: $n=4$; BAPTA: $n=4$ ), but not at the cortical pathway (right panel, control: $n=5$; BAPTA: $n=5$ ). Insets show averaged traces of 10 sweeps taken 10 min before (black) and 30 min after (gray)

\section{Cortical}

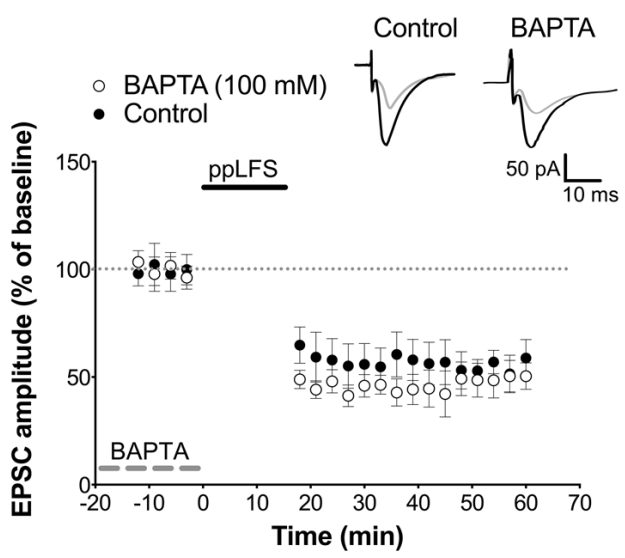

Cortical

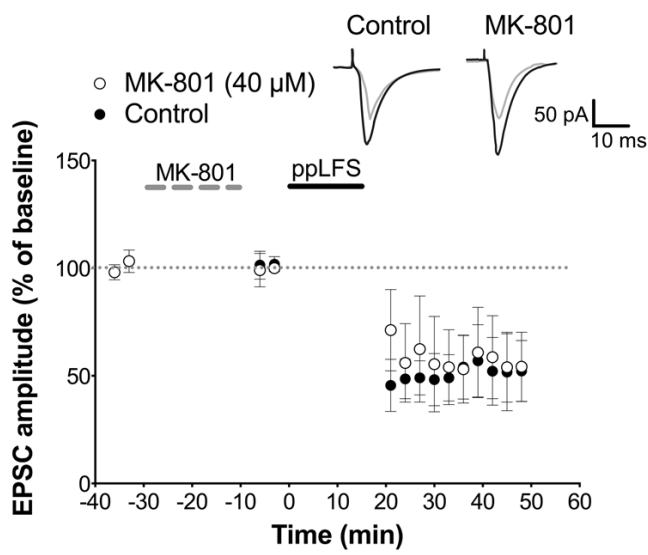

ppLFS. (B) Dialysis of MK-801 (40 $\mu$ M) blocks LA-LTD induced at the thalamic pathway (left panel, control: $n=3$; MK-801: $n=3$ ), but not at the cortical pathway (right panel, control: $n=3$; MK-801: $n=3$ ). Insets show averaged traces of 10 sweeps taken 10 min before (black) and 30 min after (gray) ppLFS. Data represent mean \pm SEM. ${ }^{*} p<0.01,{ }^{*} p<0.05$. the perirhinal and entorhinal cortex likely engage different mechanisms as well. Notably, most electrophysiological studies in the amygdala are conducted in coronal sections rather than horizontal sections (Huang and Kandel, 1998; Heinbockel and Pape, 2000; Tsvetkov et al., 2002; Humeau et al., 2003; Hong et al., 2009; Dalton et al., 2012). To our knowledge, this is the first report showing in coronal slices, a strong and reproducible induction of LTD at cortical afferents to LA by low-frequency stimulation, without the need of prior potentiation (Hong et al., 2009). As highlighted by Müller et al. (2009) this demonstrates that previous lack of LTD at cortical afferents (Tchekalarova and Albrecht, 2007; Pape and Pare, 2010) may be due to inadequate protocols for that specific pathway rather than an intrinsic failure to decrease synaptic transmission at cortical inputs to the LA. The availability of a robust LTD induction protocol at both input pathways to the amygdala in coronal slices shall allow further analyses of the mechanisms of LTD regulation in the amygdala.
Our observation that different NR2 subunits mediate the effects of ppLFS-induced LTD at both input pathways to the LA are in agreement with previous studies reporting differences in the molecular cascades at these pathways in LTP and depotentiation (Humeau et al., 2003, 2005; Hong et al., 2009; Jung et al., 2010; Meis etal., 2012). Although the distribution of NMDAR subunits in the amygdala remains largely unknown, the receptor kinetics at resting membrane potential is known to be different at cortical and thalamic pathways (Weisskopf and LeDoux, 1999). NMDARs at cortical inputs are less sensitive to magnesium blockade than at thalamic inputs, and the kinetic properties are akin to NR2C/D-containing NMDARs at the cortical pathway, but resemble NR2A/B-containing NMDARs at the thalamic pathway (Monyer etal., 1994; Weisskopf and LeDoux, 1999; Cull-Candy et al., 2001). This is in agreement with our observation that NR2C/D-containing receptors seem to mediate LTD at the cortical pathway, but not at the thalamic pathway. 
Presynaptic NR2C/D-containing NMDARs are believed to be involved in spike-timing dependent LTD in the cortex (Banerjee et al., 2009). This prompted us to investigate the site of LTD induction at both LA pathways by whole cell patch-clamp recording. We observed that LTD induction occurs post-synaptically at the thalamic pathway, but is independent of post-synaptic calcium influx or post-synaptic NMDARs at the cortical pathway. These findings for LTD complement previous reports for LTP in the amygdala showing that LTP engages different pre- and postsynaptic mechanisms at thalamic and cortical pathways (Huang and Kandel, 1998; Humeau et al., 2003, 2005, 2007; Tsvetkov et al., 2004; Rumpel et al., 2005; Shaban et al., 2006).

Although distinct NMDAR subunits and post-synaptic mechanisms are involved at thalamic and cortical afferents to the LA, both pathways converge onto a PP2B/PP1 signaling cascade. In the hippocampus, calcium influx through NMDARs, rather than other calcium channels, is specifically required for $\mathrm{PP} 2 \mathrm{~B}$ and PP1 activation (Unoki et al., 2012). It is possible that presynaptic calcium influx through NR2C/D-containing NMDARs, and postsynaptic calcium influx through NR2B-containing NMDARs, lead to the activation of $\mathrm{PP} 2 \mathrm{~B} / \mathrm{PP} 1$ at the cortical and thalamic pathway, respectively, a possibility that will need to be tested in future experiments. Whether NR2C or NR2D subunits are localized presynaptically at cortical but not at thalamic afferents to LA will also need to be determined, as well as the molecular mechanisms downstream of PP2B/PP1 activation at both pathways. In the hippocampus, PP2B and PP1 have presynaptic and post-synaptic targets (Strack et al., 1999; Nakano-Kobayashi et al., 2007; Baumgärtel and Mansuy, 2012). In hippocampal and cortical neurons, PP1 can dephosphorylate NR2B (Farinelli et al., 2012; Prabhu Ramya et al., 2012), resulting in a downregulation of NMDAR activity (Farinelli et al., 2012). Similarly, in cerebellar granule cells, PP2B downregulates NR2C expression (Suzuki et al., 2005), thus it is possible that PP2B/PP1 dephosphorylate NR2B and NR2C subunits differentially in LA in response to LTD induction. Finally, the contribution of other receptors such as metabotropic glutamate receptors (mGluRs) in LA LTD cannot be excluded. Group I mGluRs have previously been shown to contribute to ppLFS-induced depotentiation at the thalamic pathway (Kim et al., 2007), while presynaptic group II mGluRs seem to be involved at cortical afferents (Hong et al., 2009). Although mGluR-dependent LTD appears to involve tyrosine phosphatases rather than serine/threonine phosphatases such as PP2B and PP1 (Lin et al., 2005; Collingridge et al., 2010), they may also contribute to the differential molecular effects of ppLFS-induced LTD at both pathways.

LA-LTD is associated with the extinction of fear memory (Kim et al., 2007; Hong et al., 2009; Park et al., 2012). Since weakening and erasure of traumatic memory traces is critical for the management of anxiety disorders including PTSD (Kindt et al., 2009; Monfils et al., 2009; Quirk et al., 2010; Holzschneider and Mulert, 2011; Pitman et al., 2012), understanding the molecular mechanisms of LTD in the amygdala has important clinical implications. Our findings highlight the potential of therapeutically targeting PP2B/PP1 signaling to facilitate fear extinction learning in anxiety-related disorders (Baumgärtel et al., 2008; Bahi et al., 2009; Koshibu et al., 2011).

\section{ACKNOWLEDGMENTS}

We thank the reviewers for their constructive comments. We thank Urs Gerber and Mélissa Farinelli for critical reading of the manuscript and important discussions, Hansjörg Kasper for technical help, and Heiko Hörster, Gisep Bazzell, and Yvonne Zipfel for animal care. The laboratory of Isabelle M. Mansuy is supported by the University Zürich, the Swiss Federal Institute of Technology Zürich, the Swiss National Science Foundation, Roche, the National Center of Competence in Research Neural Plasticity and Repair. Johannes Bohacek is supported by a postdoc ETHZ fellowship and a Roche fellowship.

\section{REFERENCES}

Albrecht, D. (2007). Angiotensin-(1-7)-induced plasticity changes in the lateral amygdala are mediated by COX-2 and NO. Learn. Mem. 14, 177-184. doi: $10.1101 / \mathrm{lm} .425907$

Bahi, A., Mineur, Y. S., and Picciotto, M. R. (2009). Blockade of protein phosphatase $2 \mathrm{~B}$ activity in the amygdala increases anxiety- and depression-like behaviors in mice. Biol. Psychiatry 66, 1139-1146. doi: 10.1016/j.biopsych.2009.07.004

Banerjee, A., Meredith, R. M., Rodriguez-Moreno, A., Mierau, S. B., Auberson, Y. P., and Paulsen, O. (2009). Double dissociation of spike timing-dependent potentiation and depression by subunit-preferring NMDA receptor antagonists in mouse barrel cortex. Cereb. Cortex 19, 2959-2969. doi: 10.1093/cercor/ bhp067

Bartlett, T. E., Bannister, N. J., Collett, V. J., Dargan, S. L., Massey, P. V., Bortolotto, Z. A., et al. (2007). Differential roles of NR2A and NR2B-containing NMDA receptors in LTP and LTD in the CA1 region of two-week old rat hippocampus. Neuropharmacology 52, 60-70. doi: 10.1016/j.neuropharm.2006.07.013

Baumgärtel, K., Genoux, D., Welzl, H., Tweedie-Cullen, R. Y., Koshibu, K., Livingstone-Zatchej, M., et al. (2008). Control of the establishment of aversive memory by calcineurin and Zif268. Nat. Neurosci. 11, 572-578. doi: $10.1038 / \mathrm{nn} .2113$

Baumgärtel, K., and Mansuy, I. M. (2012). Neural functions of calcineurin in synaptic plasticity and memory. Learn. Mem. 19, 375-384. doi: 10.1101/lm.027201.112

Brandalise, F., Gerber, U., and Rossi, P. (2012). Golgi cell-mediated activation of postsynaptic GABA(B) receptors induces disinhibition of the Golgi cellgranule cell synapse in rat cerebellum. PLoS ONE 7:e43417. doi: 10.1371/journal.pone.0043417

Casado, M., Isope, P., and Ascher, P. (2002). Involvement of presynaptic N-methylD-aspartate receptors in cerebellar long-term depression. Neuron 33, 123-130. doi: 10.1016/S0896-6273(01)00568-2

Castaneda-Castellanos, D. R., Flint, A. C., and Kriegstein, A. R. (2006). Blind patch clamp recordings in embryonic and adult mammalian brain slices. Nat. Protoc. 1 , 532-542. doi: 10.1038/nprot.2006.75

Citri, A., and Malenka, R. C. (2008). Synaptic plasticity: multiple forms, functions, and mechanisms. Neuropsychopharmacology 33, 18-41. doi: 10.1038/sj.npp.1301559

Collingridge, G. L., Peineau, S., Howland, J. G., and Wang, Y. T. (2010). Long-term depression in the CNS. Nat. Rev. Neurosci. 11, 459-473. doi: 10.1038/nrn2867

Cull-Candy, S., Brickley, S., and Farrant, M. (2001). NMDA receptor subunits: diversity, development and disease. Curr. Opin. Neurobiol. 11, 327-335. doi: 10.1016/S0959-4388(00)00215-4

Dalton, G. L., Wang, Y. T., Floresco, S. B., and Phillips, A. G. (2008). Disruption of AMPA receptor endocytosis impairs the extinction, but not acquisition of learned fear. Neuropsychopharmacology 33, 2416-2426. doi: 10.1038/sj.npp.1301642

Dalton, G. L., Wu, D. C., Wang, Y. T., Floresco, S. B., and Phillips, A. G. (2012). NMDA GluN2A and GluN2B receptors play separate roles in the induction of LTP and LTD in the amygdala and in the acquisition and extinction of conditioned fear. Neuropharmacology 62, 797-806. doi: 10.1016/j.neuropharm.2011.09.001

Doyere, V., Schafe, G. E., Sigurdsson, T., and Ledoux, J. E. (2003). Long-term potentiation in freely moving rats reveals asymmetries in thalamic and cortical inputs to the lateral amygdala. Eur. J. Neurosci. 17, 2703-2715. doi: 10.1046/j.1460-9568.2003.02707.x

Faber, E. S., Callister, R. J., and Sah, P. (2001). Morphological and electrophysiological properties of principal neurons in the rat lateral amygdala in vitro. $J$. Neurophysiol. 85, 714-723. 
Falls, W. A., Miserendino, M. J., and Davis, M. (1992). Extinction of fearpotentiated startle: blockade by infusion of an NMDA antagonist into the amygdala. J. Neurosci. 12, 854-863.

Farinelli, M., Heitz, F. D., Grewe, B. F., Tyagarajan, S. K., Helmchen, F., and Mansuy, I. M. (2012). Selective Regulation of NR2B by Protein Phosphatase-1 for the Control of the NMDA Receptor in Neuroprotection. PLoS ONE 7:e34047. doi 10.1371/journal.pone.0034047

Feng, B., Tse, H. W., Skifter, D. A., Morley, R., Jane, D. E., and Monaghan, D. T. (2004). Structure-activity analysis of a novel NR2C/NR2D-preferring NMDA receptor antagonist: 1-(phenanthrene-2-carbonyl) piperazine-2,3-dicarboxylic acid. $\mathrm{Br}$. J. Pharmacol. 141, 508-516. doi: 10.1038/sj.bjp.0705644

Genoux, D., Haditsch, U., Knobloch, M., Michalon, A., Storm, D., and Mansuy, I. M. (2002). Protein phosphatase 1 is a molecular constraint on learning and memory. Nature 418, 970-975. doi: 10.1038/nature00928

Grilli, M., Zappettini, S., Zanardi, A., Lagomarsino, F., Pittaluga, A., Zoli, M., et al. (2009). Exposure to an enriched environment selectively increases the functional response of the pre-synaptic NMDA receptors which modulate noradrenaline release in mouse hippocampus. J. Neurochem. 110, 1598-1606. doi: 10.1111/j.1471-4159.2009.06265.x

Heinbockel, T., and Pape, H. C. (2000). Input-specific long-term depression in the lateral amygdala evoked by theta frequency stimulation. J. Neurosci. 20, RC68.

Holzschneider, K., and Mulert, C. (2011). Neuroimaging in anxiety disorders. Dialogues Clin. Neurosci. 13, 453-461.

Hong, I., Song, B., Lee, S., Kim, J., Kim, J., and Choi, S. (2009). Extinction of cued fear memory involves a distinct form of depotentiation at cortical input synapses onto the lateral amygdala. Eur. J. Neurosci. 30, 2089-2099. doi: 10.1111/j.1460 9568.2009.07004.x

Hrabetova, S., Serrano, P., Blace, N., Tse, H. W., Skifter, D. A., Jane, D. E., et al. (2000). Distinct NMDA receptor subpopulations contribute to long-term potentiation and long-term depression induction. J. Neurosci. 20, RC81.

Huang, Y. Y., and Kandel, E. R. (1998). Postsynaptic induction and PKAdependent expression of LTP in the lateral amygdala. Neuron 21, 169-178. doi: 10.1016/S0896-6273(00)80524-3

Humeau, Y., Herry, C., Kemp, N., Shaban, H., Fourcaudot, E., Bissiere, S., et al. (2005). Dendritic spine heterogeneity determines afferent-specific Hebbian plasticity in the amygdala. Neuron 45, 119-131. doi: 10.1016/j.neuron.2004 12.019

Humeau, Y., Reisel, D., Johnson, A. W., Borchardt, T., Jensen, V., Gebhardt, C., et al. (2007). A pathway-specific function for different AMPA receptor subunits in amygdala long-term potentiation and fear conditioning. J. Neurosci. 27, 1094710956. doi: 10.1523/JNEUROSCI.2603-07.2007

Humeau, Y., Shaban, H., Bissiere, S., and Luthi, A. (2003). Presynaptic induction of heterosynaptic associative plasticity in the mammalian brain. Nature 426, 841845. doi: 10.1038/nature02194

Johansen, J. P., Cain, C. K., Ostroff, L. E., and Ledoux, J. E. (2011). Molecular mechanisms of fear learning and memory. Cell 147, 509-524. doi 10.1016/j.cell.2011.10.009

Jouvenceau, A., Billard, J. M., Haditsch, U., Mansuy, I. M., and Dutar, P. (2003). Different phosphatase-dependent mechanisms mediate long-term depression and depotentiation of long-term potentiation in mouse hippocampal CAl area. Eur. J. Neurosci. 18, 1279-1285. doi: 10.1046/j.1460-9568.2003.02831.x

Jouvenceau, A., Hedou, G., Potier, B., Kollen, M., Dutar, P., and Mansuy, I. M. (2006). Partial inhibition of PP1 alters bidirectional synaptic plasticity in the hippocampus. Eur. J. Neurosci. 24, 564-572. doi: 10.1111/j.1460-9568.2006 04938.x

Jung, S. Y., Kim, J., Kwon, O. B., Jung, J. H., An, K., Jeong, A. Y., et al. (2010) Input-specific synaptic plasticity in the amygdala is regulated by neuroligin-1 via postsynaptic NMDA receptors. Proc. Natl. Acad. Sci. U.S.A. 107, 4710-4715. doi: 10.1073/pnas.1001084107

Kim, J., Lee, S., Park, K., Hong, I., Song, B., Son, G., et al. (2007). Amygdala depotentiation and fear extinction. Proc. Natl. Acad. Sci. U.S.A. 104, 20955-20960. doi: 10.1073/pnas.0710548105

Kindt, M., Soeter, M., and Vervliet, B. (2009). Beyond extinction: erasing human fear responses and preventing the return of fear. Nat. Neurosci. 12, 256-258. doi: $10.1038 / \mathrm{nn} .2271$

Kirkwood, A., Dudek, S. M., Gold, J. T., Aizenman, C. D., and Bear, M. F. (1993). Common forms of synaptic plasticity in the hippocampus and neocortex in vitro. Science 260, 1518-1521. doi: 10.1126/science.8502997
Koshibu, K., Graff, J., and Mansuy, I. M. (2011). Nuclear protein phosphatase-1: an epigenetic regulator of fear memory and amygdala long-term potentiation. Neuroscience 173, 30-36. doi: 10.1016/j.neuroscience.2010.11.023

Lin, C. H., Lee, C. C., and Gean, P. W. (2003a). Involvement of a calcineurin cascade in amygdala depotentiation and quenching of fear memory. Mol. Pharmacol. 63, 44-52. doi: 10.1124/mol.63.1.44

Lin, C. H., Yeh, S. H., Leu, T. H., Chang, W. C., Wang, S. T., and Gean, P. W. (2003b) Identification of calcineurin as a key signal in the extinction of fear memory. J. Neurosci. 23, 1574-1579.

Lin, C. H., Lee, C. C., Huang, Y. C., Wang, S. J., and Gean, P. W. (2005). Activation of group II metabotropic glutamate receptors induces depotentiation in amygdala slices and reduces fear-potentiated startle in rats. Learn. Mem. 12, 130-137. doi: $10.1101 / \mathrm{lm} .85304$

Lisman, J. E., and Zhabotinsky, A. M. (2001). A model of synaptic memory: a CaMKII/PP1 switch that potentiates transmission by organizing an AMPA receptor anchoring assembly. Neuron 31, 191-201. doi: 10.1016/S08966273(01)00364-6

Liu, J. L., Li, M., Dang, X. R., Wang, Z. H., Rao, Z. R., Wu, S. X., et al. (2009). A NMDA receptor antagonist, MK-801 impairs consolidating extinction of auditory conditioned fear responses in a Pavlovian model. PLoS ONE 4:e7548. doi: 10.1371/journal.pone.0007548.

Liu, L., Wong, T. P., Pozza, M. F., Lingenhoehl, K., Wang, Y., Sheng, M., et al. (2004). Role of NMDA receptor subtypes in governing the direction of hippocampal synaptic plasticity. Science 304, 1021-1024. doi: 10.1126/science. 1096615

Loftis, J. M., and Janowsky, A. (2003). The N-methyl-D-aspartate receptor subunit NR2B: localization, functional properties, regulation, and clinical implications. Pharmacol. Ther. 97, 55-85. doi: 10.1016/S0163-7258(02)00302-9

Malleret, G., Haditsch, U., Genoux, D., Jones, M. W., Bliss, T. V., Vanhoose, A. M., et al. (2001). Inducible and reversible enhancement of learning, memory, and long-term potentiation by genetic inhibition of calcineurin. Cell 104, 675-686. doi: 10.1016/S0092-8674(01)00264-1

Mameli, M., Carta, M., Partridge, L. D., and Valenzuela, C. F. (2005). Neurosteroidinduced plasticity of immature synapses via retrograde modulation of presynaptic NMDA receptors. J. Neurosci. 25, 2285-2294. doi: 10.1523/JNEUROSCI.387704.2005

Mansuy, I. M., Mayford, M., Jacob, B., Kandel, E. R., and Bach, M. E. (1998). Restricted and regulated overexpression reveals calcineurin as a key component in the transition from short-term to long-term memory. Cell 92, 39-49. doi: 10.1016/S0092-8674(00)80897-1

Mansuy, I. M., and Shenolikar, S. (2006). Protein serine/threonine phosphatases in neuronal plasticity and disorders of learning and memory. Trends Neurosci. 29, 679-686. doi: 10.1016/j.tins.2006.10.004

Massey, P. V., Johnson, B. E., Moult, P. R., Auberson, Y. P., Brown, M. W., Molnar, E., et al. (2004). Differential roles of NR2A and NR2B-containing NMDA receptors in cortical long-term potentiation and long-term depression. J. Neurosci. 24, 7821-7828. doi: 10.1523/JNEUROSCI.1697-04.2004

McKernan, M. G., and Shinnick-Gallagher, P. (1997). Fear conditioning induces a lasting potentiation of synaptic currents in vitro. Nature 390, 607-611. doi: $10.1038 / 37605$

Meis, S., Endres, T., and Lessmann, V. (2012). Postsynaptic BDNF signalling regulates long-term potentiation at thalamo-amygdala afferents. J. Physiol. 590, 193-208. doi: 10.1113/jphysiol.2011.220434

Mitsuhashi, S., Matsuura, N., Ubukata, M., Oikawa, H., Shima, H., and Kikuchi, K. (2001). Tautomycetin is a novel and specific inhibitor of serine/threonine protein phosphatase type 1, PP1. Biochem. Biophys. Res. Commun. 287, 328-331. doi: 10.1006/bbrc.2001.5596

Miwa, H., Fukaya, M., Watabe, A. M., Watanabe, M., and Manabe, T. (2008). Functional contributions of synaptically localized NR2B subunits of the NMDA receptor to synaptic transmission and long-term potentiation in the adult mouse CNS. J. Physiol. 586, 2539-2550. doi: 10.1113/jphysiol.2007.147652

Monfils, M. H., Cowansage, K. K., Klann, E., and Ledoux, J. E. (2009). Extinctionreconsolidation boundaries: key to persistent attenuation of fear memories. Science 324, 951-955. doi: 10.1126/science.1167975

Monyer, H., Burnashev, N., Laurie, D. J., Sakmann, B., and Seeburg, P. H. (1994). Developmental and regional expression in the rat brain and functional properties of four NMDA receptors. Neuron 12, 529-540. doi: 10.1016/08966273(94)90210-0 
Morishita, W., Connor, J. H., Xia, H., Quinlan, E. M., Shenolikar, S., and Malenka, R. C. (2001). Regulation of synaptic strength by protein phosphatase 1. Neuron 32, 1133-1148. doi: 10.1016/S0896-6273(01)00554-2

Mulkey, R. M., Endo, S., Shenolikar, S., and Malenka, R. C. (1994). Involvement of a calcineurin/inhibitor-1 phosphatase cascade in hippocampal long-term depression. Nature 369, 486-488. doi: 10.1038/369486a0

Mulkey, R. M., Herron, C. E., and Malenka, R. C. (1993). An essential role for protein phosphatases in hippocampal long-term depression. Science 261, 1051-1055. doi: 10.1126/science.8394601

Müller, T., Albrecht, D., and Gebhardt, C. (2009). Both NR2A and NR2B subunits of the NMDA receptor are critical for long-term potentiation and long-term depression in the lateral amygdala of horizontal slices of adult mice. Learn. Mem. 16, 395-405. doi: 10.1101/lm.1398709

Nakano-Kobayashi, A., Yamazaki, M., Unoki, T., Hongu, T., Murata, C., Taguchi, R., et al. (2007). Role of activation of PIP5Kgamma661 by AP-2 complex in synaptic vesicle endocytosis. EMBO J. 26, 1105-1116. doi: 10.1038/sj.emboj. 7601573

Oberbeck, D. L., Mccormack, S., and Houpt, T. A. (2010). Intra-amygdalar okadaic acid enhances conditioned taste aversion learning and CREB phosphorylation in rats. Brain Res. 1348, 84-94. doi: 10.1016/j.brainres.2010.06.029

Pape, H. C., and Pare, D. (2010). Plastic synaptic networks of the amygdala for the acquisition, expression, and extinction of conditioned fear. Physiol. Rev. 90, 419-463. doi: 10.1152/physrev.00037.2009

Park, S., Lee, S., Kim, J., and Choi, S. (2012). Ex vivo depotentiation of conditioninginduced potentiation at thalamic input synapses onto the lateral amygdala requires GluN2B-containing NMDA receptors. Neurosci. Lett. 530, 121-126. doi: 10.1016/j.neulet.2012.10.011

Pi, H. J., and Lisman, J. E. (2008). Coupled phosphatase and kinase switches produce the tristability required for long-term potentiation and long-term depression. J. Neurosci. 28, 13132-13138. doi: 10.1523/JNEUROSCI.2348-08.2008

Pitman, R. K., Rasmusson, A. M., Koenen, K. C., Shin, L. M., Orr, S. P., Gilbertson, M. W., et al. (2012). Biological studies of post-traumatic stress disorder. Nat. Rev. Neurosci. 13, 769-787. doi: 10.1038/nrn3339

Prabhu Ramya, R., Suma Priya, S., Mayadevi, M., and Omkumar, R. V. (2012). Regulation of phosphorylation at $\operatorname{Ser}(1303)$ of GluN2B receptor in the postsynaptic density. Neurochem. Int. 61, 981-985. doi: 10.1016/j.neuint.2012.08.016

Quirk, G. J., Pare, D., Richardson, R., Herry, C., Monfils, M. H., Schiller, D., et al. (2010). Erasing fear memories with extinction training. J. Neurosci. 30, 14993-14997. doi: 10.1523/JNEUROSCI.4268-10.2010

Rodriguez-Moreno, A., Banerjee, A., and Paulsen, O. (2010). Presynaptic NMDA receptors and spike timing-dependent depression at cortical synapses. Front. Synaptic Neurosci. 2:18. doi: 10.3389/fnsyn.2010.00018

Rodriguez-Moreno, A., and Paulsen, O. (2008). Spike timing-dependent long-term depression requires presynaptic NMDA receptors. Nat. Neurosci. 11, 744-745. doi: $10.1038 / \mathrm{nn} .2125$

Rogan, M. T., Staubli, U. V., and Ledoux, J. E. (1997). Fear conditioning induces associative long-term potentiation in the amygdala. Nature 390, 604-607. doi: $10.1038 / 37601$

Rumpel, S., Ledoux, J., Zador, A., and Malinow, R. (2005). Postsynaptic receptor trafficking underlying a form of associative learning. Science 308, 83-88. doi: 10.1126/science.1103944

Ryu, J., Futai, K., Feliu, M., Weinberg, R., and Sheng, M. (2008). Constitutively active Rap2 transgenic mice display fewer dendritic spines, reduced extracellular signal-regulated kinase signaling, enhanced long-term depression, and impaired spatial learning and fear extinction. J. Neurosci. 28, 8178-8188. doi: 10.1523/JNEUROSCI.1944-08.2008

Samson, R. D., Dumont, E. C., and Pare, D. (2003). Feedback inhibition defines transverse processing modules in the lateral amygdala. J. Neurosci. 23, 1966-1973.

Samson, R. D., and Pare, D. (2006). A spatially structured network of inhibitory and excitatory connections directs impulse traffic within the lateral amygdala. Neuroscience 141, 1599-1609. doi: 10.1016/j.neuroscience.2006. 04.077

Shaban, H., Humeau, Y., Herry, C., Cassasus, G., Shigemoto, R., Ciocchi, S., et al (2006). Generalization of amygdala LTP and conditioned fear in the absence of presynaptic inhibition. Nat. Neurosci. 9, 1028-1035. doi: 10.1038/nn1732

Sjostrom, P. J., Turrigiano, G. G., and Nelson, S. B. (2003). Neocortical LTD via coincident activation of presynaptic NMDA and cannabinoid receptors. Neuron 39, 641-654. doi: 10.1016/S0896-6273(03)00476-8
Sotres-Bayon, F., Bush, D. E., and Ledoux, J. E. (2007). Acquisition of fear extinction requires activation of $\mathrm{NR} 2 \mathrm{~B}$-containing $\mathrm{NMDA}$ receptors in the lateral amygdala. Neuropsychopharmacology 32, 1929-1940. doi: 10.1038/sj.npp.1301316

Strack, S., Kini, S., Ebner, F. F., Wadzinski, B. E., and Colbran, R. J. (1999). Differential cellular and subcellular localization of protein phosphatase 1 isoforms in brain. J. Comp. Neurol. 413, 373-384. doi: 10.1002/(SICI)10969861(19991025)413:3<373::AID-CNE2>3.0.CO;2-Z

Suzuki, K., Sato, M., Morishima, Y., and Nakanishi, S. (2005). Neuronal depolarization controls brain-derived neurotrophic factor-induced upregulation of NR2C NMDA receptor via calcineurin signaling. J. Neurosci. 25, 9535-9543. doi: 10.1523/JNEUROSCI.2191-05.2005

Tchekalarova, J., and Albrecht, D. (2007). Angiotensin II suppresses long-term depression in the lateral amygdala of mice via L-type calcium channels. Neurosci. Lett. 415, 68-72. doi: 10.1016/j.neulet.2006.12.040

Thompson, C. L., Drewery, D. L., Atkins, H. D., Stephenson, F. A., and Chazot, P. L. (2002). Immunohistochemical localization of N-methyl-D-aspartate receptor subunits in the adult murine hippocampal formation: evidence for a unique role of the NR2D subunit. Brain Res. Mol. Brain Res. 102, 55-61. doi: 10.1016/S0169328X(02)00183-3

Tsvetkov, E., Carlezon, W. A., Benes, F. M., Kandel, E. R., and Bolshakov, V. Y. (2002). Fear conditioning occludes LTP-induced presynaptic enhancement of synaptic transmission in the cortical pathway to the lateral amygdala. Neuron 34, 289-300. doi: 10.1016/S0896-6273(02)00645-1

Tsvetkov, E., Shin, R. M., and Bolshakov, V. Y. (2004). Glutamate uptake determines pathway specificity of long-term potentiation in the neural circuitry of fear conditioning. Neuron 41, 139-151. doi: 10.1016/S0896-6273(03)00800-6

Unoki, T., Matsuda, S., Kakegawa, W., Van, N. T., Kohda, K., Suzuki, A., et al. (2012). NMDA receptor-mediated PIP5K activation to produce $\mathrm{PI}(4,5) \mathrm{P}$ is essential for AMPA receptor endocytosis during LTD. Neuron 73, 135-148. doi: 10.1016/j.neuron.2011.09.034

von Bohlen und Halbach, O., and Albrecht, D. (2002). Reciprocal connections of the hippocampal area CA1, the lateral nucleus of the amygdala and cortical areas in a combined horizontal slice preparation. Neurosci. Res. 44, 91-100. doi: 10.1016/S0168-0102(02)00092-5

Wang, S. J., and Gean, P. W. (1999). Long-term depression of excitatory synaptic transmission in the rat amygdala. J. Neurosci. 19, 10656-10663.

Weisskopf, M. G., and LeDoux, J. E. (1999). Distinct populations of NMDA receptors at subcortical and cortical inputs to principal cells of the lateral amygdala. J. Neurophysiol. 81, 930-934.

Yang, J., Chamberlain, S. E., Woodhall, G. L., and Jones, R. S. (2008). Mobility of NMDA autoreceptors but not postsynaptic receptors at glutamate synapses in the rat entorhinal cortex. J. Physiol. 586, 4905-4924. doi: 10.1113/jphysiol.2008.157974

Yasuda, H., Higashi, H., Kudo, Y., Inoue, T., Hata, Y., Mikoshiba, K., et al. (2003) Imaging of calcineurin activated by long-term depression-inducing synaptic inputs in living neurons of rat visual cortex. Eur. J. Neurosci. 17, 287-297. doi: 10.1046/j.1460-9568.2003.02449.x

Yu, S. Y., Wu, D. C., and Zhan, R. Z. (2010). GluN2B subunits of the NMDA receptor contribute to the AMPA receptor internalization during long-term depression in the lateral amygdala of juvenile rats. Neuroscience 171, 1102-1108. doi: 10.1016/j.neuroscience.2010.09.038

Conflict of Interest Statement: The authors declare that the research was conducted in the absence of any commercial or financial relationships that could be construed as a potential conflict of interest.

Received: 30 April 2014; paper pending published: 07 June 2014; accepted: 16 June 2014; published online: 03 July 2014.

Citation: Mirante O, Brandalise F, BohacekJ and Mansuy IM (2014) Distinct molecular components for thalamic- and cortical-dependent plasticity in the lateral amygdala. Front. Mol. Neurosci. 7:62. doi: 10.3389/fnmol.2014.00062

This article was submitted to the journal Frontiers in Molecular Neuroscience.

Copyright (c) 2014 Mirante, Brandalise, Bohacek and Mansuy. This is an open-access article distributed under the terms of the Creative Commons Attribution License (CC BY). The use, distribution or reproduction in other forums is permitted, provided the original author(s) or licensor are credited and that the original publication in this journal is cited, in accordance with accepted academic practice. No use, distribution or reproduction is permitted which does not comply with these terms. 